\section{BMJ Open Respiratory Research}

\title{
Endobronchial valves for emphysema: an individual patient-level reanalysis of randomised controlled trials
}

\author{
Karin Klooster, ${ }^{1}$ Dirk-Jan Slebos, ${ }^{1}$ Zaid Zoumot, ${ }^{2}$ Claire Davey, ${ }^{3}$ Pallav L Shah, ${ }^{3}$ \\ Nicholas S Hopkinson ${ }^{3}$
}

To cite: Klooster K,

Slebos D-J, Zoumot Z, et al. Endobronchial valves for emphysema: an individual patient-level reanalysis of randomised controlled trials. BMJ Open Resp Res 2017;4:e000214. doi:10.1136/ bmjresp-2017-000214

Received 15 May 2017 Revised 10 October 2017 Accepted 11 October 2017

\section{CrossMark}

${ }^{1}$ Department of Pulmonary Diseases, University of Groningen, University Medical Center Groningen, Groningen, The Netherlands

${ }^{2}$ Respiratory and Critical Care Institute, Cleveland Clinic Abu Dhabi, Abu Dhabi, United Arab Emirates

${ }^{3}$ NIHR Respiratory Biomedical Research Unit, Royal Brompton and Harefield NHS Foundation Trust and Imperial College, London, UK

Correspondence to Dr Nicholas S Hopkinson; n.hopkinson@ic.ac.uk

\section{ABSTRACT}

Introduction Endobronchial valve placement has potential as a treatment for patients with chronic obstructive pulmonary disease (COPD). However, a robust evidence base will be needed to convince commissioners of healthcare that it is a high-value treatment. We sought to develop the evidence base by performing an individual patient-level analysis of randomised controlled trials in people with heterogeneous emphysema and an absence of collateral ventilation.

Methods A literature search (PROSPER0 register CRD42016048127) identified two trials meeting these criteria, the BelieVeR-HIFi and STELVIO studies. Anonymised individual patient data were obtained from investigators and analysed. The primary outcome measure was a comparison of change in forced expiratory volume in $1 \mathrm{~s}\left(\mathrm{FEV}_{1}\right)$ from baseline between the treatment and control groups. Secondary end points were change from baseline in 6 min walk distance (6MWD), Medical Research Council dyspnoea score and St George's Respiratory Questionnaire (SGRQ).

Results 114 individuals were treated with 3-month to 6-month follow-up data available for 101 individuals. $\mathrm{FEV}_{1}$ improved by $23.1( \pm 28.3) \%$ in patients treated with valves with a mean $(95 \% \mathrm{Cl})$ difference in response between groups of $17.8(26.5,9.2) \%(p<0.0001)$. Relative to controls valve placement was associated with a fall in residual volume of $0.64(0.43,0.86) L(p<0.0001)$, a 9.5 $(3.5,15.6)$ unit fall in SGRQ $(p=0.0022)$ and a $64.2(94.0$, $34.5) \mathrm{m}$ increase in 6MWD. There were three deaths in the treatment arm and the pneumothorax rate was $15 \%$. Conclusions These data strengthen the evidence that endobronchial valve treatment can produce clinically meaningful improvements in appropriately selected COPD patients.

\section{BACKGROUND}

Chronic obstructive pulmonary disease (COPD) is characterised by the presence of bronchitis and emphysema. The latter process, due to breakdown of elastic alveolar tissue, leads to increased lung compliance and gas trapping. Lung hyperinflation worsens with exercise leading to breathlessness and is associated with reduced physical activity ${ }^{1}{ }^{2}$ and reduced survival. ${ }^{3}$ Inhaled bronchodilator medications have

\section{Key messages}

Can endobronchial valve placement improve health outcomes in selected patients with heterogeneous emphysema and an absence of collateral ventilation

- Endobronchial valves improve lung function, exercise capacity and health status at $3-6$ months after the procedure

Combining patient-level data from randomised controlled trials of bronchoscopic lung volume reduction with endobronchial valves strengthens the evidence that this therapy can improve lung function, exercise capacity and quality of life in appropriately selected patients with heterogeneous emphysema and absence of interlobar collateral ventilation.

only modest impacts on symptoms and do not alter the natural history of the disease. In selected patients with a heterogeneous pattern of emphysema, surgical resection can be targeted at the worst affected areas of lung tissue which contribute disproportionately to gas trapping and hyperinflation, and so improve respiratory mechanics. ${ }^{45}$ Lung volume reduction surgery (LVRS) improves symptoms and prolongs survival ${ }^{6-8}$ but can be associated with significant morbidity and a risk of death, with a cost per quality adjusted life year (QALY) of at least $\$ 40000 .^{9}$

A more recent approach has been to instead use endobronchial valves to occlude the airways supplying the worst affected part of the lung. ${ }^{10-13}$ This is intended to cause atelectasis in the target lobe, with a similar impact on the function of the rest of the lung as seen in LVRS. However, atelectasis will only occur in the absence of significant collateral ventilation between the target lobe and the adjacent one. Because of this, the success rate of valve placement in early studies was low, impacting on the value of endobronchial valves as a therapeutic intervention. ${ }^{13-15}$ Collateral ventilation can now be measured directly using the Chartis pressure/flow catheter system. ${ }^{16-18}$ 
Case series and single-centre trials have demonstrated that endobronchial valve treatment in patients with emphysema can lead to improvements in symptoms, lung function and exercise capacity, ${ }^{11-13}$ reductions in dynamic hyperinflation ${ }^{19}$ and improvements in oxygen kinetics ${ }^{20}$ and chest wall synchrony. ${ }^{21}$ Moreover, where target lobe volume loss is seen on CT, a substantial survival benefit has been observed compared with those where valve treatment has been ineffective. ${ }^{1415}$

We wished to combine data from existing single-centre studies to address the question 'in patients with emphysema and a target lobe with proven absence of interlobar collateral ventilation, what is the effect of endobronchial valves placed to achieve lobar occlusion, on lung function, exercise capacity and health status?'

\section{METHODS}

The study was registered on the PROSPERO International prospective register of systematic reviews CRD42016048127. We searched PubMed using the terms 'endobronchial valves (AND) emphysema' on 22 September 2016. This identified 116 abstracts. Twelve of these were clinical trials. Review of the abstracts identified two trials where patients with emphysema were randomised to endobronchial valve placement or standard care with identification of the presence of interlobar collateral ventilation using the Chartis system (Pulmonx). ${ }^{11}{ }^{12}$ Complete, anonymised, individual patient data were obtained from the investigators for analysis.

Data were checked for: missing items, internal data consistency and randomisation integrity. Summary tables were checked with the trial protocol and latest trial report or publication.

The primary outcome measure was a comparison of change in forced expiratory volume in $1 \mathrm{~s}\left(\mathrm{FEV}_{1}\right)$ between the endobronchial valve treatment and control groups. Secondary end points were change from baseline to 3 months (BeLieVeR-HIFi) or to 6 months (STELVIO) in $6 \mathrm{~min}$ walk distance (6MWD), Medical Research Council (MRC) dyspnoea score and St George's Respiratory Questionnaire (SGRQ). The different time points in the two trials were merged as a measure of the effectiveness of the intervention because the impactof the intervention was expected to be much greater than spontaneous decline over a short period of time. Statistical analysis was carried out using StatView 5. Changes were compared between treatment and control groups using unpaired t-tests. Analysis of covariance using baseline values as a covariate together with treatment allocation and which study individuals were in was used to establish whether responses differed by study. Collateral ventilaion

\section{Table 1 Baseline characteristics}

\begin{tabular}{|c|c|c|c|c|}
\hline & All $n=114$ & Control $n=59$ & Treatment $n=55$ & $P$ value (t-test) \\
\hline Age (years) & $60.2(8.6)$ & $60.7(8.1)$ & $59.7(9.1)$ & 0.5 \\
\hline Per cent female & 55 & 66 & 44 & 0.016 \\
\hline BMI $\left(\mathrm{kg} / \mathrm{m}^{2}\right)$ & $24.4(4.2)$ & $24.3(4.1)$ & $24.4(4.3)$ & 0.90 \\
\hline $\mathrm{mMRC}$ & $2.7(0.6)$ & $2.7(0.56)$ & $2.7(0.70)$ & 0.74 \\
\hline Smoking (pack/years) & $43.5(23.3)$ & $42.2(22.6)$ & $44.7(24.1)$ & 0.56 \\
\hline SGRQ symptoms & $59.4(20.0)$ & $61.2(20.7)$ & $57.5(19.2)$ & 0.32 \\
\hline SGRQ activity & 85.7 (10.9) & $87.2(9.8)$ & $84.0(11.8)$ & 0.12 \\
\hline SGRQ impacts & $50.7(17.3)$ & $51.3(17.2)$ & $50.0(17.7)$ & 0.68 \\
\hline SGRQ total & $63.0(13.5)$ & $64.1(13.2)$ & $61.8(13.9)$ & 0.36 \\
\hline $\mathrm{FEV}_{1}(\mathrm{~L})$ & $0.86(.30)$ & $0.82(0.28)$ & $0.90(0.32)$ & 0.14 \\
\hline $\mathrm{FEV}_{1} \%$ pred & $30.6(8.8)$ & $30.5(8.9)$ & $30.6(8.9)$ & 0.95 \\
\hline TLC \%pred & $133.6(13.2)$ & $137.0(13.1)$ & $130.0(12.5)$ & 0.004 \\
\hline RV \%pred & $222.5(37.9)$ & $230.5(39.2)$ & $213.8(34.8)$ & 0.018 \\
\hline $\mathrm{RV} / \mathrm{TLC}$ & $60.7(8.4)$ & $62.4(8.1)$ & $58.8(8.5)$ & 0.026 \\
\hline FRC \%pred & $188.5(29.7)$ & $198.5(29.3)$ & $176.5(26.2)$ & 0.011 \\
\hline Tlco \%pred & $37.7(9.8)$ & $37.2(9.8)$ & $38.1(9.8)$ & 0.65 \\
\hline $\mathrm{PaCO}_{2} \mathrm{kPa}$ & $9.4(1.3)$ & $5.0(0.6)$ & $5.0(0.9)$ & 0.66 \\
\hline $\mathrm{PaO}_{2} \mathrm{kPa}$ & $9.4(1.3)$ & $9.3(1.1)$ & $9.4(1.5)$ & 0.52 \\
\hline 6 min walk distance $(\mathrm{m})$ & $360(87)$ & $359(85)$ & $361(89)$ & 0.89 \\
\hline BODE score & $5.9(1.3)$ & $5.9(1.2)$ & $5.9(1.4)$ & 0.87 \\
\hline
\end{tabular}

BMI, body mass index; BODE, BMI, obstruction, dyspnoea, exercise capacity; FEV ${ }_{1}$, forced expiratory volume in $1 \mathrm{~s}$; FRC, functional residual capacity; mMRC, modified Medical Research Council dyspnoea score; $\mathrm{PaCO}_{2}$, arterial carbon dioxide tension; $\mathrm{PaO}_{2}$, arterial oxygen tension; RV, residual volume; SGRQ, St George's Respiratory Questionnaire; TLC, total lung capacity. 


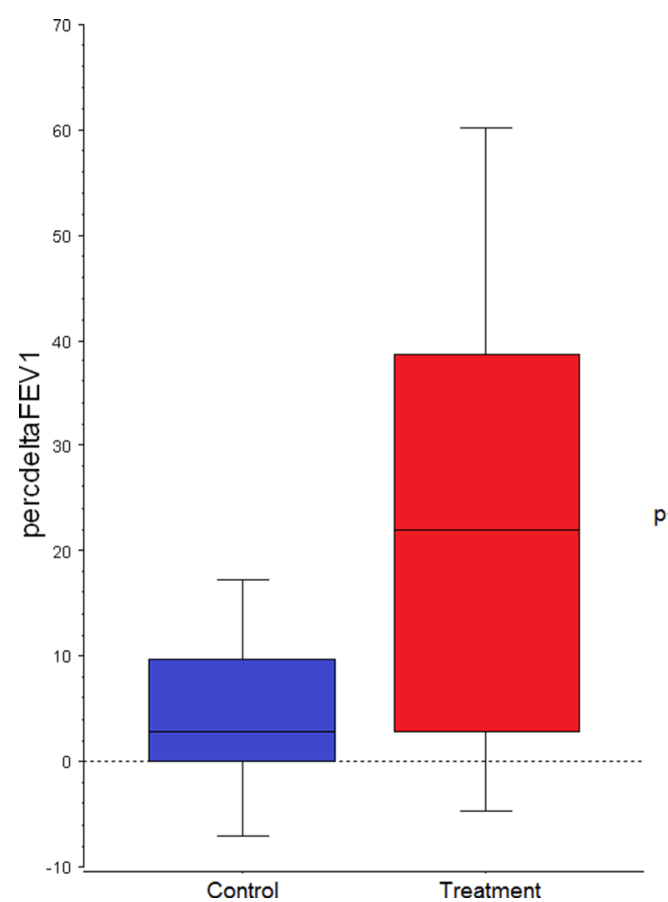

Figure 1 Percentage change in forced expiratory volume in $1 \mathrm{~s}\left(\mathrm{FEV}_{1}\right)$ in patients treated with endobronchial valves and control subjects. Boxes represent 25th-75th percentiles, bars 10th-90th percentiles $(P<0.0001)$.

(CV)-positive patients $(\mathrm{n}=4)$ treated in the BeLieVeR-HIFi were excluded.

No ethical approval for this reanalysis of anonymised data was obtained.

\section{RESULTS}

Literature search identified two studies. The UK-based BeLieVeR-HIFi trial (ISRCTN04761234) was a

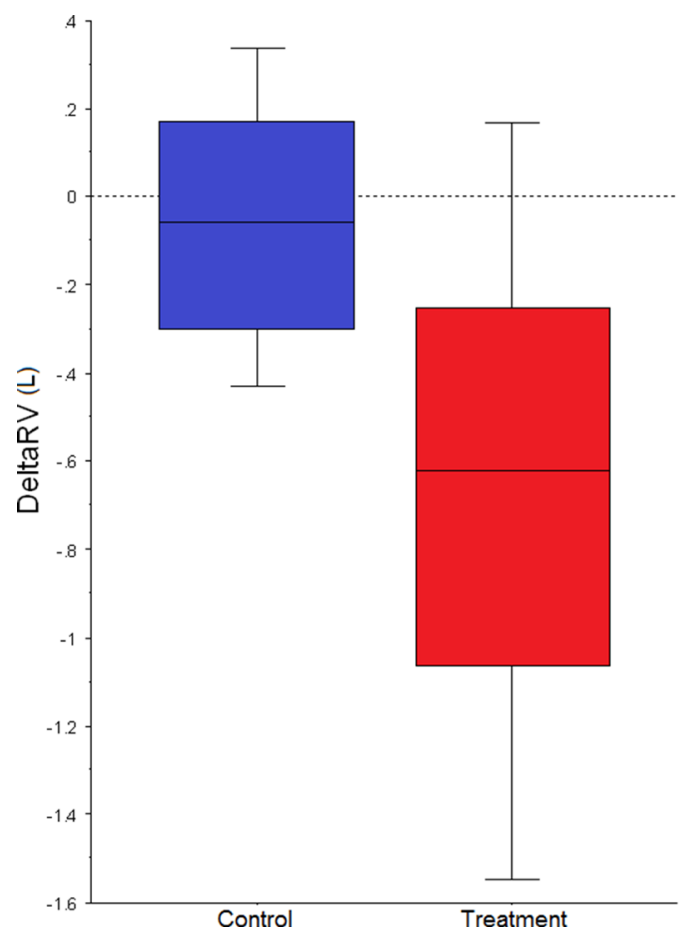

$p<0.0001$

Figure 2 Change in residual volume (RV) in patients treated with endobronchial valves and control subjects. Boxes represent 25th-75th percentiles, bars 10th-90th percentiles $(P<0.0001)$.

double-blind study which randomised 50 patients on a one-to-one basis to endobronchial valve placement, intended to achieve lobar occlusion ${ }^{11}$ or to bronchoscopy with a sham-bronchoscopy procedure. Patients were selected on the basis of hyperinflation, heterogeneous emphysema and interlobar fissure adjacent to the target lobe which appeared to be at least $90 \%$

\begin{tabular}{|c|c|c|c|c|}
\hline & Control, $n=57$ & Endobronchial valves, $n=44$ & Between-group difference $(95 \% \mathrm{Cl})$ & t-test \\
\hline$\Delta \mathrm{FEV}_{1}(\mathrm{~mL})$ & $40(17)$ & $185(70)$ & 150 (60 to 230$)$ & 0.0006 \\
\hline$\Delta \mathrm{FEV}_{1}(\%)$ & $5.3(14.7)$ & $23.1(28.3)$ & $17.8(26.5$ to 9.2$)$ & $<0.0001$ \\
\hline$\triangle \mathrm{SGRQ}$ symptoms & $-5.9(15.2)$ & $-4.7(22.8)$ & $1.2(8.7$ to 6.4$)$ & 0.76 \\
\hline$\triangle$ SGRQ activity & $-0.3(10.8)$ & $-14.7(20.9)$ & $-14.4(-8.0$ to 20.7$)$ & $<0.0001$ \\
\hline$\triangle$ SGRQ impacts & $-3.7(13.2)$ & $-14.2(22.2)$ & $-10.4(-3.3$ to 17.5$)$ & 0.004 \\
\hline$\triangle \mathrm{SGRQ}$ total & $-3.2(9.8)$ & $-12.7(20.0)$ & $-9.5(-3.5$ to 15.6$)$ & 0.0022 \\
\hline$\triangle \mathrm{TLC}(\mathrm{L})$ & $0.02(0.6)$ & $-0.45(0.47)$ & $-0.47(-0.22$ to 0.73$)$ & 0.0004 \\
\hline$\Delta \mathrm{RV}(\mathrm{L})$ & $-0.06(0.36)$ & $-0.70(0.52)$ & $-0.64(-0.425$ to 0.863$)$ & $<0.0001$ \\
\hline$\triangle \mathrm{RV} / \mathrm{TLC}(\%)$ & $-0.7(3.4)$ & $-5.95(7.3)$ & $-5.2(-3.0$ to 7.4$)$ & $<0.0001$ \\
\hline$\triangle \mathrm{FRC}(\mathrm{L})$ & $0.82(0.48)$ & $-0.53(0.66)$ & $-0.61(-0.38$ to 0.83$)$ & $<0.0001$ \\
\hline$\Delta$ Tlco(\% predicted) & $0.02(12.8)$ & $5.80(14.6)$ & 5.7 (11.6 to 0.03$)$ & 0.051 \\
\hline$\triangle \mathrm{PaCO}_{2}(\mathrm{kPa})$ & $-0.01(0.43)$ & $-0.14(0.59)$ & $-0.13(0.07$ to 0.34$)$ & 0.02 \\
\hline$\Delta \mathrm{PaO}_{2}(\mathrm{kPa})$ & $0.21(0.97)$ & $-0.29(1.1)$ & $-0.50(0.07$ to 0.93$)$ & 0.03 \\
\hline$\triangle 6 M W D(\mathrm{~m})$ & $-5.6(61.1)$ & $58.6(87.2)$ & 64.2 (94.0 to 34.5$)$ & $<0.0001$ \\
\hline
\end{tabular}

6MWD, 6min walk distance; $\mathrm{FEV}_{1}$, forced expiratory volume in $1 \mathrm{~s} ; \mathrm{FRC}$, functional residual capacity; $\mathrm{PaCO}_{2}$, arterial carbon dioxide tension; $\mathrm{PaO}_{2}$, arterial oxygen tension; RV, residual volume; SGRQ, St George's Respiratory Questionnaire; TIco, carbon monoxide transfer factor. 


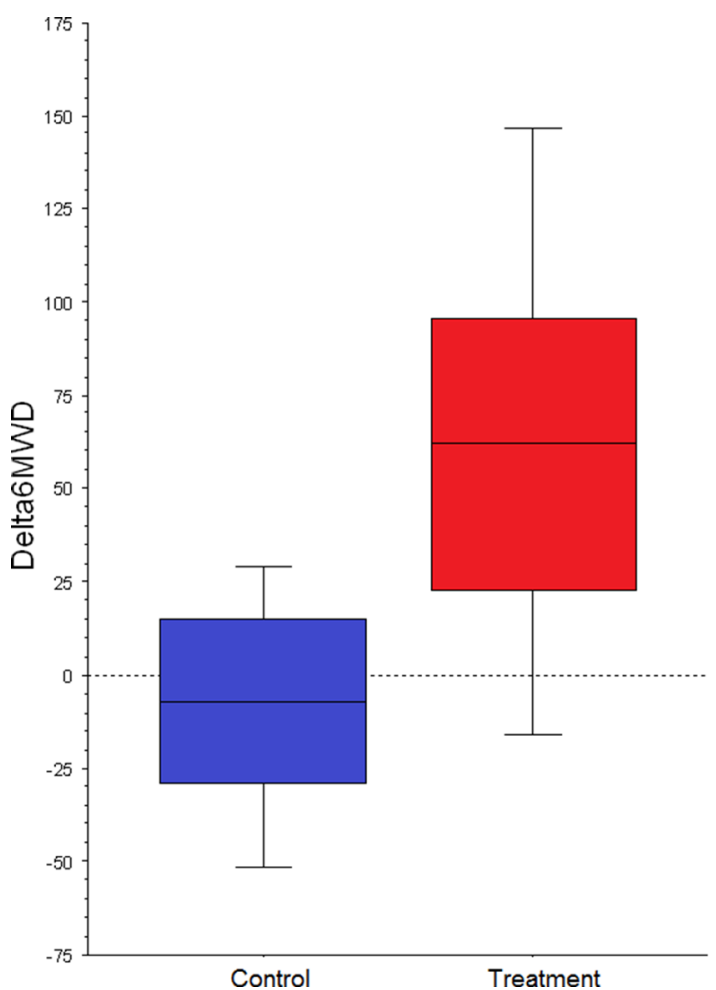

Figure 3 Change in 6 min walk distance (6MWD) in patients treated with endobronchial valves and contro subjects. Boxes represent 25th-75th percentiles, bars 10th-90th percentiles $(\mathrm{P}<0.0001)$.

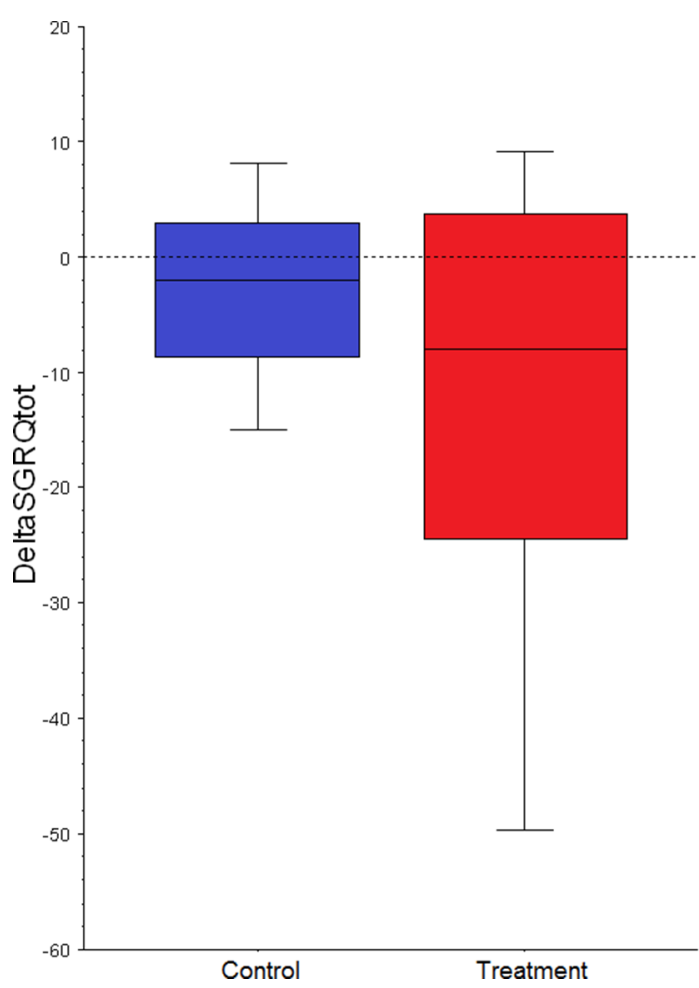

$p=0.0022$

Figure 4 Change in St George's Respiratory Questionnaire (SGRQc) in patients treated with endobronchial valves and control subjects. Boxes represent 25th-75th percentiles, bars 10th-90th percentiles ( $P=0.0022)$.

\begin{tabular}{lcc|}
\hline Table 3 Serious adverse events & & \\
\hline & $\begin{array}{l}\text { Treatment, Control, } \\
\mathbf{n}=\mathbf{5 5}\end{array}$ & $\mathbf{n = 5 9}$ \\
\hline $\begin{array}{l}\text { Exacerbations requiring } \\
\text { hospitalisation }\end{array}$ & 9 & 5 \\
$\begin{array}{l}\text { Pneumonia (respiratory tract } \\
\text { infection with X-ray changes) }\end{array}$ & 4 & 1 \\
$\begin{array}{l}\text { Pneumothorax } \\
\text { Deaths }\end{array}$ & 8 & 1 \\
\hline Respiratory failure & 3 & 0 \\
\hline COPD with cor pulmonale & 2 & 0 \\
\hline
\end{tabular}

COPD, chronic obstructive pulmonary disease.

intact. Allocation was by predetermined block randomisation, obtained by telephone link from the bronchoscopy suite after the patient had been sedated. Collateral ventilation was measured but patients were treated even if $\mathrm{CV}$ positive $(\mathrm{n}=4)$. For the purpose of the present analysis, the CV-positive patients were excluded, as they fall outside the hypothesis being addressed. Outcome measures were assessed at 3 months post procedure by investigators blind to study allocation. There were two deaths in the treatment arm, one because of complications of a valve removal procedure and one from cor pulmonale. One control patient was too unwell to attend for follow-up, so follow-up data were available for 24 control patients and 19 treated patients.

A second Dutch study (STELVIO trial-Netherlands Trial Register number, NTR2876) randomised 68 hyperinflated COPD patients, with a target lobe based on visual inspection of the CT, on a one-to-one basis to endobronchial valve placement or usual care. ${ }^{12}$ Allocation was performed using a randomisation list that had been computer-generated in blocks of four. The generated codes were placed in opaque-sealed envelopes, which were numbered sequentially. The assigned envelope was opened before bronchoscopy in the presence of the patient and bronchoscopist. Bronchoscopy was then performed. Eighty-four patients entered the study, but patients with collateral ventilation $(n=13)$ or airways unsuitable for endobronchial valve placement $(n=3)$ were excluded. Pulmonary function tests were assessed 6 months following the procedure by blinded assessors. One control patient withdrew. One treated patient died due to end-stage COPD with respiratory failure 58 days after treatment and one was withdrawn from the study by the investigators because of a prolonged admission to the critical care unit due to COPD exacerbation caused by a viral infection. Seven patients discontinued the study because their valves had been removed-two at patient request because of perceived lack of efficacy, two because of bronchial torsion, two because of recurrent pneumothorax and one because of pneumonia distal to valve. Follow-up data for this 
study were therefore available for 25 treated patients and 33 controls.

The BeLieVeR-HIFi trial was funded by the Efficacy and Mechanism Evaluation Programme, funded by the MRC and managed by the National Institute for Health Research (NIHR) on behalf of the MRC-NIHR partnership (EME 10/90/10). The valves used in the trial were provided free of charge by the device company, Pulmonx. The STELVIO trial was supported by a grant (171101008, to the University Medical Centre Groningen) from the Netherlands Organisation for Health Research and Development (ZonMw) and by innovation funding from the University Medical Centre Groningen. Valves were obtained commercially from Pulmonx (all catheters at regular market prices and all valves at $50 \%$ of the market list price).

Baseline data for 114 patients were available, $55 \%$ female, aged mean (SD) 60.2 (8.6) years, with a mean (SD) $\mathrm{FEV}_{1} 30.6$ (8.9)\% predicted, with follow-up data available for 101 (treatment $n=44$ and control $n=57$ ). The groups were well matched for spirometry, gas transfer, symptoms, exercise capacity and BODE (BMI, obstruction, dyspnoea, exercise capacity) score, but the control group were more hyperinflated (table 1 ).

$\mathrm{FEV}_{1}$ improved by $23.1( \pm 28.3) \%$ in patients treated with valves with a mean $(95 \% \mathrm{CI})$ difference in response between groups of $17.8(26.5,9.2) \%(\mathrm{P}<0.0001)$ (figure 1 , table 2). Valve placement was associated with statistically and clinically significant improvements in lung volumes (figure 2), exercise capacity (figure 3) and quality of life (figure 4). Outcomes did not differ significantly between the two trials for change in $\mathrm{FEV}_{1}$, residual volume 6MWD or SGRQ ( $\mathrm{P}=0.79,0.28,0.16$ and 0.21 , respectively) although MRC dyspnoea score improved to a greater extent in the STELVIO study $(\mathrm{P}=0.002)$

Adverse events are described in table 3 . There were a total of eight pneumothoraces in the treatment arm and one in a control subject during the follow-up period.

\section{DISCUSSION}

The present data combine results from two randomised controlled trials which evaluated the impact of endobronchial valve placement to achieve lobar occlusion in patients with heterogeneous emphysema, where collateral ventilation had been excluded using the Chartis catheter system. ${ }^{11}{ }^{12}$ They further strengthen the evidence that endobronchial valve treatment can, in appropriately selected patients, produce clinically meaningful improvements in lung function, exercise capacity and health status. The amplitudes of changes exceeded conventionally defined minimum clinically important differences (MCID) - a $15 \%$ increase for $\mathrm{FEV}_{1}, 350 \mathrm{~mL}$ reduction for the residual volume, ${ }^{22}$ an increase of $26 \mathrm{~m}$ for the $6 \mathrm{MWD}^{23}$ and a 4 -point decrease in the SGRQc. ${ }^{24}{ }^{25}$ It also exceeds the more recently proposedMCID of 7 SGRQ points at 6 months for bronchoscopic interventions in advanced COPD. ${ }^{26}$

\section{Methodological issues}

We combined data from two studies which were similar in that they randomised patients with severe emphysema and a suitable target lobe to endobronchial valve placement or usual care. The trials were well conducted with study methodology including allocation and blinding clearly described with a low risk of bias. There were a number of differences between the studies, though we do not feel that they preclude combining the data as we have done. Follow-up was at 3 months in the BeLieVeR-HIFi study ${ }^{11}$ and 6 months in STELVIO, ${ }^{12}$ but the size of the response observed is significantly larger than the likely spontaneous decline over that time period. The former study included a control bronchoscopy, so participants were blind to treatment allocation whereas treatment was open label in STELVIO. This might have influenced response to questionnaires or exercise tests which are effort dependent, but in fact, improvements in these with treatment were similar between studies. Of note, the improvement in SGRQ score exceeded the 8-point threshold used in the National Emphysema Treatment Trial to allow for the lack of blinding in that study. ${ }^{6}$

\section{Hazards of therapy}

Our study extends the data available on harms associated with endobronchial valve placement. Acute exacerbation-like events are common in the early period after valve placemen. Pneumothorax remains a significant concern, occurring in $15 \%$ of individuals treated. Pneumothoraces occur because the valve placement has been effective, causing a change in the conformation of the lung which leads to tearing and air leakage. For this reason, pneumothorax was unusual in early trials, ${ }^{13}$ but the rate has increased as selection criteria for trials have become more precise. ${ }^{111227}$ Most of these episodes respond to conventional treatment with an intercostal drain but they can be fatal, especially in a group of patients who already have significant ventilatory limitation. It is therefore recommended that patients should be observed for several days as an inpatient following the procedure.

\section{CONCLUSION}

This analysis provides further evidence for the efficacy of endobronchial valves as a therapeutic option in COPD patients with advanced emphysema. Longer-term data are becoming available suggesting that benefits, including survival benefits, ${ }^{14}$ of valve treatment are sustained and suggest that this may be a relatively high-value therapy in $\mathrm{COPD},{ }^{28}$ with a cost per QALY of approximately $€ 25000 .{ }^{29}$ Good outcomes from lung volume procedures will depend on a multidisciplinary approach and the development of effective referral pathways. ${ }^{782830}$ Further work is needed to establish the relative long-term benefits of valve placement and LVRS. TheComparative Effectiveness of Lung volume reduction surgery for eEphysema and Bronchociopic valve placement (CELEB) trial is 
now underway to address this http://www.isrctn.com/ ISRCTN19684749

This analysis was supported by the NIHR Respiratory Biomedical Research Unit at Royal Brompton and Harefield NHS Foundation Trust and Imperial College, London, UK.

Contributors KK, ZZ, CD, D-JS and PLS conceived the study and developed the search strategy. NSH performed the literature search, collected data, performed the analysis and wrote the first draft to which all authors contributed. All authors have approved the submitted version. NSH is the guarantor.

Funding This analysis was supported by the NIHR Respiratory Biomedical Research Unit at Royal Brompton and Harefield NHS Foundation Trust and Imperial College, London, UK.

Competing interests All authors have completed the ICMJE uniform disclosure form at www.icmje.org/coi_disclosure.pdf. NSH was principal investigator in a UK NIHR funded trial (BeLieVeR-HIFi) for which PulmonX provided endobronchial valves free of charge. PLS has been an investigator on studies funded by PulmonX, Uptake, Holaria, CSA Medical, Uptake Medical, Olympus and PneumRx/BTG and received consultancy fees from for Broncus, CSA Medical, Medtronic, Olympus, PneumRx/BTG and Pulmonx. KK received lecture fees from Pulmonx and devices for treatments, travel support, and grant support from PneumRx/BTG and Pulmonx. D-JS has been an investigator on studies funded by CSA Medical, Holaira, PulmonX and PneumRx/BTG and received consultancy fees from CSA Medical, Holaira, PneumRx/BTG and Pulmonx.

Provenance and peer review Not commissioned; externally peer reviewed.

Data sharing statement Requests to access the data can be made to the corresponding author.

Open Access This is an Open Access article distributed in accordance with the Creative Commons Attribution Non Commercial (CC BY-NC 4.0) license, which permits others to distribute, remix, adapt, build upon this work non-commercially, and license their derivative works on different terms, provided the original work is properly cited and the use is non-commercial. See: http://creativecommons.org/ licenses/by-nc/4.0/

(c) Article author(s) (or their employer(s) unless otherwise stated in the text of the article) 2017. All rights reserved. No commercial use is permitted unless otherwise expressly granted.

\section{REFERENCES}

1. Gimeno-Santos E, Frei A, Steurer-Stey C, et al. Determinants and outcomes of physical activity in patients with COPD: a systematic review. Thorax 2014;69:731-9.

2. Shrikrishna D, Patel M, Tanner RJ, et al. Quadriceps wasting and physical inactivity in patients with COPD. Eur Respir $J$ 2012;40:1115-22

3. Casanova C, Cote C, de Torres JP, et al. Inspiratory-to-total lung capacity ratio predicts mortality in patients with chronic obstructive pulmonary disease. Am J Respir Crit Care Med 2005;171:591-7.

4. Fessler HE, Scharf SM, Permutt S. Improvement in spirometry following lung volume reduction surgery: application of a physiologic model. Am J Respir Crit Care Med 2002;165:34-40.

5. Hopkinson NS, Sharshar T, Ross ET, et al. Corticospinal control of respiratory muscles in chronic obstructive pulmonary disease. Respir Physiol Neurobiol 2004;141:1-12.

6. Criner GJ, Cordova F, Sternberg AL, et al. The National Emphysema Treatment Trial (NETT) Part II: Lessons learned about lung volume reduction surgery. Am J Respir Crit Care Med 2011;184:881-93.

7. Clark SJ, Zoumot Z, Bamsey O, et al. Surgical approaches for lung volume reduction in emphysema. Clin Med 2014;14:122-7.
8. Greening NJ, Williams JEA, Hussain SF, et al. An early rehabilitation intervention to enhance recovery during hospital admission for an exacerbation of chronic respiratory disease: randomised controlled trial, 2014.

9. Ramsey SD, Sullivan SD, Kaplan RM. Cost-effectiveness of lung volume reduction surgery. Proc Am Thorac Soc 2008;5:406-11.

10. Toma TP, Hopkinson NS, Hillier J, et al. Bronchoscopic volume reduction with valve implants in patients with severe emphysema. Lancet 2003;361:931-3.

11. Davey C, Zoumot Z, Jordan S, et al. Bronchoscopic lung volume reduction with endobronchial valves for patients with heterogeneous emphysema and intact interlobar fissures (the BeLieVeR-HIFi study): a randomised controlled trial. Lancet 2015;386:1066-73.

12. Klooster $\mathrm{K}$, ten Hacken $\mathrm{NH}$, Hartman JE, et al. Endobronchial Valves for Emphysema without Interlobar Collateral Ventilation. $N$ Engl J Med 2015;373:2325-35.

13. Sciurba FC, Ernst A, Herth FJ, et al. A randomized study of endobronchial valves for advanced emphysema. N Engl J Med 2010;363:1233-44.

14. Garner J, Kemp SV, Toma TP, et al. Survival after endobronchial valve placement for emphysema: A 10-year follow-up study. Am J Respir Crit Care Med 2016;194:519-21.

15. Hopkinson NS, Kemp SV, Toma TP, et al. Atelectasis and survival after bronchoscopic lung volume reduction for COPD. Eur Respir J 2011;37:1346-51.

16. Schuhmann M, Raffy P, Yin Y, et al. Computed tomography predictors of response to endobronchial valve lung reduction treatment. Comparison with Chartis. Am J Respir Crit Care Med 2015;191:767-74.

17. Herth FJ, Eberhardt R, Gompelmann D, et al. Radiological and clinical outcomes of using Chartis ${ }^{\mathrm{TM}}$ to plan endobronchial valve treatment. Eur Respir J 2013;41:302-8.

18. Koster TD, van Rikxoort EM, Huebner $\mathrm{RH}$, et al. Predicting lung volume reduction after endobronchial valve therapy is maximized using a combination of diagnostic tools. Respiration 2016;92:150-7.

19. Hopkinson NS, Toma TP, Hansell DM, et al. Effect of bronchoscopic lung volume reduction on dynamic hyperinflation and exercise in emphysema. Am J Respir Crit Care Med 2005;171:453-60.

20. Faisal A, Zoumot Z, Shah PL, et al. Effective bronchoscopic lung volume reduction accelerates exercise oxygen uptake kinetics in emphysema. Chest 2016;149:435-46.

21. Zoumot Z, LoMauro A, Aliverti $A$, et al. Lung volume reduction in emphysema improves chest wall asynchrony. Chest 2015;148:185-95.

22. Hartman JE, Ten Hacken $\mathrm{NH}$, Klooster $\mathrm{K}$, et al. The minimal important difference for residual volume in patients with severe emphysema. Eur Respir J 2012;40:1137-41.

23. Puhan MA, Chandra D, Mosenifar Z, et al. The minimal important difference of exercise tests in severe COPD. Eur Respir J 2011;37:784-90.

24. Meguro M, Barley EA, Spencer S, et al. Development and validation of an improved, copd-specific version of the st. George respiratory questionnaire. Chest 2007;132:456-63.

25. Schünemann HJ, Puhan M, Goldstein R, et al. Measurement properties and interpretability of the Chronic respiratory disease questionnaire (CRQ). COPD 2005;2:81-9

26. Welling JB, Hartman JE, Ten Hacken $\mathrm{NH}$, et al. The minimal important difference for the St George's respiratory questionnaire in patients with severe COPD. Eur Respir J 2015;46:1598-604.

27. Valipour A, Slebos DJ, Herth F, et al. Endobronchial Valve Therapy in Patients with Homogeneous Emphysema. Results from the IMPACT study. Am J Respir Crit Care Med 2016;194:1073-82.

28. Zoumot Z, Jordan S, Hopkinson NS. Emphysema: time to say farewell to therapeutic nihilism. Thorax 2014;69:973-5.

29. Pietzsch JB, Garner A, Herth FJ. Cost-effectiveness of endobronchial valve therapy for severe emphysema: a model-based projection based on the VENT study. Respiration 2014;88:389-98.

30. McNulty W, Jordan S, Hopkinson NS. Attitudes and access to lung volume reduction surgery for COPD: a survey by the British Thoracic Society. BMJ Open Respir Res 2014;1:e000023. 